\title{
SARS-CoV-2 antibody seroprevalence in Lebanon: findings from the first nationwide serosurvey
}

\author{
Abbas Hoballah', Rana El Haidari2 ${ }^{2}$, Ghina Siblany ${ }^{3}$, Fadi Abdel Sater ${ }^{4}$, Samir Mansour ${ }^{5}$, Hamad Hassan ${ }^{6,7}$ and \\ Linda Abou-Abbas ${ }^{8,9}$ [D
}

\begin{abstract}
Background: Lebanon, a small country in the Middle East, remains severely affected by the COVID-19 pandemic. Seroprevalence surveys of anti-SARS-CoV-2 antibodies provide accurate estimates of SARS-CoV-2 infection and hence evaluate the extent of the pandemic. The present study aimed to evaluate the prevalence of SARS-CoV-2 antibodies in Lebanon and to compare the estimated cumulative number of COVID-19 cases with the officially registered number of laboratory-confirmed cases up to January 15, 2021.
\end{abstract}

Methods: A nationwide population-based serosurvey study was conducted in Lebanon between December 7, 2020, and January 15, 2021, before the initiation of the national vaccination program. The nCOVID-19 IgG \& IgM point-of-care (POCT) rapid test was used to detect the presence of anti-SARS-COV-2 immunoglobulin G (IgG) in the blood. Seroprevalence was estimated after weighting for sex, age, and area of residence and adjusting for the test performance.

Results: Of the 2058 participants, 329 were positive for IgG SARS-COV-2, resulting in a crude seroprevalence of 16.0\% (95\% Cl 14.4-17.6). The weighed seroprevalence was 15.9\% (95\% Cl of 14.4 and 17.4). After adjusting for test performance, the population weight-adjusted seroprevalence was $18.5 \%(95 \% \mathrm{Cl} 16.8-20.2)$. This estimate implies that 895,770 individuals of the general population were previously infected by COVID-19 up to January 15, 2021 in Lebanon. The overall estimated number of subjects with previous SARS-CoV-2 infection was three times higher than the officially reported cumulative number of confirmed cases. Seroprevalence was similar across age groups and sexes ( $p$-value > 0.05). However, significant differences were revealed across governorates.

Conclusions: Our results suggest that the Lebanese population is still susceptible to SARS-CoV-2 infection and far from achieving herd immunity. These findings represent an important contribution to the surveillance of the COVID19 pandemic in Lebanon and to the understanding of how this virus spreads. Continued surveillance for COVID-19 cases and maintaining effective preventive measures are recommended to control the epidemic spread in conjunction with a national vaccination campaign to achieve the desired level of herd immunity against COVID-19.

Keywords: SARS-CoV-2 antibody, Seroprevalence, Lebanon, Serosurvey

*Correspondence: Ranahaidari14@hotmail.com

2 Department of Research, Islamic Health Society, Baabda, Lebanon

Full list of author information is available at the end of the article

\section{Background}

The global epidemic of coronavirus disease 2019 (COVID-19) has presented a major threat to public health worldwide [1]. The clinical manifestations of infection with the severe acute respiratory syndrome coronavirus

(c) The Author(s) 2022. Open Access This article is licensed under a Creative Commons Attribution 4.0 International License, which permits use, sharing, adaptation, distribution and reproduction in any medium or format, as long as you give appropriate credit to the original author(s) and the source, provide a link to the Creative Commons licence, and indicate if changes were made. The images or other third party material in this article are included in the article's Creative Commons licence, unless indicated otherwise in a credit line to the material. If material is not included in the article's Creative Commons licence and your intended use is not permitted by statutory regulation or exceeds the permitted use, you will need to obtain permission directly from the copyright holder. To view a copy of this licence, visit http://creativecommons.org/licenses/by/4.0/. The Creative Commons Public Domain Dedication waiver (http://creativeco mmons.org/publicdomain/zero/1.0/) applies to the data made available in this article, unless otherwise stated in a credit line to the data. 
2 (SARS-CoV-2) extend from asymptomatic infections (1.2\%), mild cases (80.9\%), severe cases (13.8\%), to critical illness $(4.7 \%)$ which can lead to death $(2.3 \%)$ [2, 3]. Lebanon, a small country in the Middle East, remains severely affected by the COVID-19 pandemic. The first detected COVID-19 case in Lebanon was reported by the Ministry of Public Health (MOPH) on February 21, 2020, after a 45 -year-old woman returning from Iran tested positive. Immediately, the patient and her traced contacts were quarantined. On February 22, Lebanon shut down public transport and banned flights to countries that had experienced exponential growth patterns of COVID19, including Iran, Italy, China, and South Korea. A few days later, several measures were imposed to reduce the spread of the infection, including enforced partial curfew hours, as well as closing daycare centers, schools, universities, malls, restaurants, tourist sites, public gardens, nightclubs, pubs, gyms, and theaters. By mid-March, with the number of confirmed cases climbing to 99, the Lebanese government declared a state of health emergency and imposed a 2-week full lockdown including the closure of the Beirut Rafic Hariri International Airport, as well as sea and land ports except for diplomatic missions and cargo aircrafts. On April 27, a phased reopening was initiated after a decrease in the average growth factor per week from 4.6 in week 2 (February 28-March 5) to less than 1 in week 6 (March 27-April 2). On July 1st, 2021, the Lebanese government decided to reopen Beirut Airport. However, at the end of July, a few weeks after reopening the airport, there was a significant rise in the number of COVID-19 patients in various districts. Thus, community transmission was declared. Exploration of the epidemic spread using data provided by the MOPH until June 30, 2020 revealed that the initial value of the reproductive transmission factor (R0) was remarkably high at $\mathrm{R} 0=5.6$. However, it significantly decreased to $\mathrm{R} 1=0.52$ after 32 days, before rising moderately to 1.1 after 90 days following a partial relaxation of social distancing measures [4]. After the devastating explosion that occurred at the Beirut Port on August 4, 2020, the daily number of new cases increased to 500-1000 between August and mid-September, then to 1000-2000 from Mid-September to December. In January 2021, the country experienced its first large wave when the number of daily confirmed cases climbed up reaching 6000 on 14 January 2021 [5]. After this peak, the curve went down following lockdown measures, with a relative increase in March 2021. Between April and June 2021, a continuous decline in the confirmed daily cases occurred. However, in July 2021, the daily number of new cases started a new increase, approaching 1500 per day. As of 6 August 2021, the time-varying reproduction number, calculated as the average number of secondary infections caused by a single infected person at a given time, was estimated as 1.25 [confidence interval (CI) of 1.17-1.34] suggesting that the number of new infections and the rate of transmission were increasing [6]. Figure 1 illustrates the epidemic curve of laboratory confirmed cases in Lebanon starting February 21 and up to August 6, 2021 [7].

Diagnostic testing for SARS-CoV-2 infections, including rapid antigen testing or polymerase chain reaction (PCR)-based viral RNA testing, is a critical component to the overall prevention and control strategy for COVID19 [8]. Mass screening were undertaken by the Lebanese government to contain the spread of the epidemic, including testing the contacts of positive cases, people possibly exposed by travel-related affairs, or individuals showing symptoms [9]. Nevertheless, the majority of the population remained untested due to several factors. To name a few, we had limited availability and accessibility of testing, high cost of the reverse transcription-polymerase chain reaction (RT-PCR) test, stigma or simply

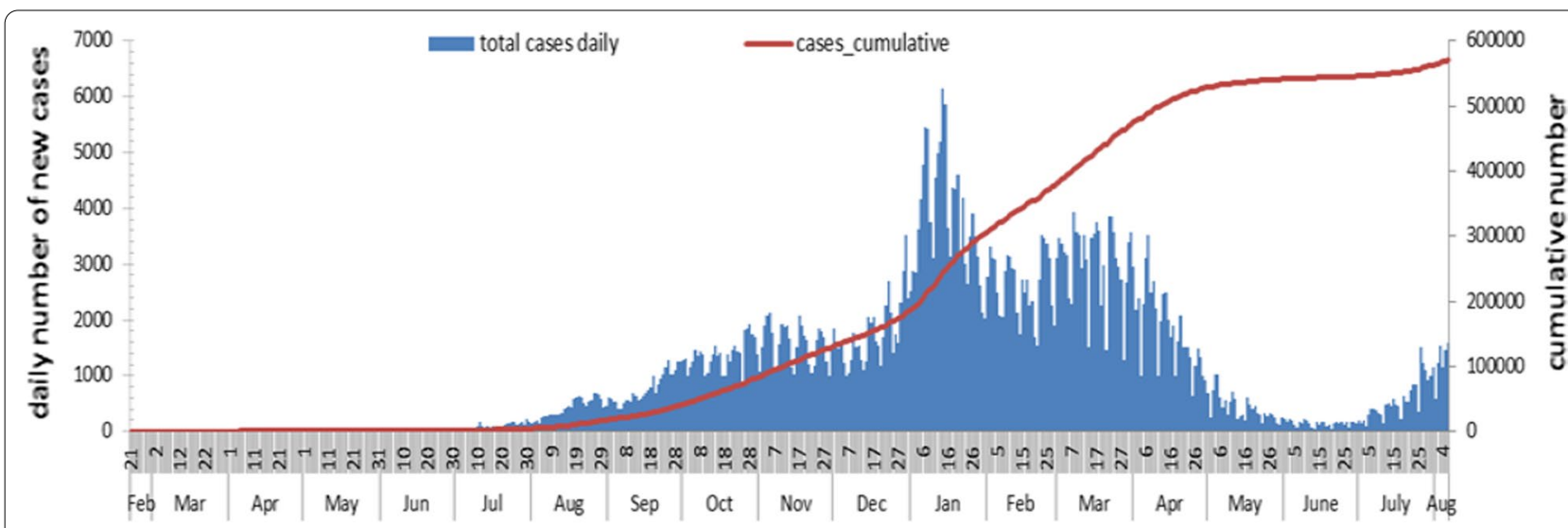

Fig. 1 The epidemic curve of laboratory confirmed cases of COVID-19 in Lebanon starting from February 21, 2021 until August 6, 2021 [7] 
the lack of perceived need especially among mild and asymptomatic cases [9]. Thus, the number of confirmed SARS-CoV-2 infections is likely to be significantly underestimated. Consequently, epidemiological surveillance of confirmed COVID-19 cases might catch only a proportion of all SARS-COV-2 infections, and the epidemic curves might not be representative of the disease true burden in the community.

Recently, the World Health Organization (WHO) has recommended conducting seroprevalence surveys to determine the presence of anti-SARS-CoV-2 antibodies in blood samples and evaluate the extent of the COVID19 pandemic [10]. Thus, several nationwide studies have been conducted to estimate the seroprevalence of SARSCoV-2 antibodies (IgG and/or IgM) among the general population [11-18]. Data from these studies can be used as a reference in the evaluation of the implemented preventive measures and in optimizing COVID-19 vaccine distribution.

At the time of writing, no seroprevalence studies were conducted for refining estimates of COVID-19 cases and transmission and hence, evaluating the pandemic impact on the Lebanese society. Thus, the present study objectives were to estimate the prevalence of SARS-CoV-2 antibodies in a representative large sample of citizens and to compare the estimated number of cases with the officially registered number of laboratory confirmed cases reported by the MOPH up to until January 15, 2021.

\section{Methods}

\section{Study design and population}

A nationwide population-based serosurveillance study was conducted in Lebanon between December 7, 2020 and January 15, 2021, before the initiation of the national vaccination program. The Lebanese Republic, a country in the Levant region of western Asia and the transcontinental region of the Middle East, is composed of eight governorates (Beirut, Mount Lebanon, North Lebanon, Akkar, Baalbek El-Hermel, Bekaa, Nabatieh, and South Lebanon) including 24 districts.

All residents who were deemed to be asymptomatic for SARS-CoV-2 infection at the time of data collection were eligible to participate. The exclusion criteria included patients confirmed with SARS-CoV-2 infection, individuals under quarantine, and patients presenting symptoms suggestive of SARS-CoV-2 infection including cough, fever, body aches, and shortness of breath [19], as well as those who refused to give informed consent.

\section{Sample size}

The sample size was calculated using the Epi Info ${ }^{\mathrm{TM}}$ tool (Center for Disease Control, Atlanta, GA, USA available from http://wwwn.cdc.gov/epiinfo/) [20]. The sample size was calculated based on an estimated COVID-19 prevalence of $16 \%$ based on a previous study result [21], a confidence interval of $95 \%$, a maximum allowable error in the prevalence of $1 \%$, a non-response rate of $10 \%$, and a Lebanese population size of 4,842,000 inhabitants based on the latest Lebanese census data [22]. The minimum required sample size was 2170 . The total number of participants who accepted to participate was 2058, making the response rate $95 \%$.

\section{Sampling procedure}

A stratified random sampling method was used in this survey to select a representative sample from across Lebanon's eight governorates. The number of participants in each governorate was calculated using a probability-proportion-to-size sampling method based on the data provided by the Central Administration of Statistics (CAS) in 2019 (Table 1) [22]. In each governorate, six villages were randomly selected from a list provided by the CAS except for North Lebanon and Akkar governorates where only two and three villages had been selected respectively, giving a total of 41 villages. Within each village, a random starting point was selected by the research team who visited a fixed number of households to enroll one person from each. In case of participation refusal or no one at home, the team proceeded to the next house and completed the survey until the required number of households was enrolled from each village. A table of the number of participants according to Lebanese governates and villages has been provided in the Additional file 1.

\section{Data collection}

Fieldwork was conducted by professional teams from the Islamic Health Society who were responsible for data collection and blood sampling. All fieldwork members

Table 1 Regional distribution of the study population

\begin{tabular}{llclc}
\hline Governorates & $\begin{array}{l}\text { Population } \\
\text { size }\end{array}$ & $\begin{array}{l}\text { Percentages } \\
\text { of } \\
\text { population }\end{array}$ & $\begin{array}{l}\text { Estimated } \\
\text { sample } \\
\text { size }\end{array}$ & $\begin{array}{l}\text { Collected } \\
\text { sample }\end{array}$ \\
\hline Beirut & 342,000 & 7 & 153 & 162 \\
$\begin{array}{l}\text { Mount Leba- } \\
\text { non }\end{array}$ & 203,3000 & 42 & 911 & 925 \\
North Lebanon & 638,000 & 13 & 286 & 163 \\
Akkar & 324,000 & 7 & 145 & 119 \\
Bekaa & 298,000 & 6 & 134 & 143 \\
Baalbek El- & 245,000 & 5 & 110 & 112 \\
Hermel & & 12 & 262 & 269 \\
South Lebanon & 584,000 & 8 & 170 & 165 \\
Nabatieh & 379,000 & 100 & 2170 & 2058 \\
Lebanon & $4,842,000$ & & & \\
\hline
\end{tabular}


underwent infection-control training and were provided with personal protective equipment. During the visit, the interviewer explained the purpose of the study to potential participants. After obtaining informed consent, the interviewers used a paper-based survey to collect data on sociodemographic characteristics (age, sex, and residency), clinical information about comorbidities, history of positive PCR testing for SARS-CoV-2 and previous symptoms suggestive of COVID-19. Upon sample collection, trained laboratory personnel analyzed the serological test, and the participants were promptly informed about the test results thereafter. Positive cases, as well as cases with suggestive symptoms of COVID-19, were reported to the MOPH surveillance system. Data entry was performed and double-checked by researchers not involved in the data collection process. Then, anonymized data were saved on a secure server.

\section{Serological analyses}

Serological testing was conducted by the point-of-care test (nCOVID-19 IgG \& IgM POCT; Corso Vittorio Emanuele II,15,20122, Milano, ITALIA) applied as per the manufacturer's instructions by pricking finger and applying a drop of blood to a test strip. This test is a lateral-flow immunochromatographic assay for qualitative differentiation between IgG and IgM against the receptor binding domain of SARS-CoV-2 spike (S) protein. This is a simple cassette-based test that works with just 10-20 $\mu \mathrm{l}$ of serum, plasma or whole blood. This serum test can be used by a health care professional outside the laboratory settings and yields results in ten minutes. The manufacturer reported clinical sensitivity of $90.0 \%$ and a specificity of $96.3 \%$. An in-house validation study, using a set of sera from 25 negative controls and 25 RT-PCRconfirmed SARS-CoV-2 infection cases was conducted to estimate test performance. This validation pilot study revealed sensitivity of $92.3 \%$ and a specificity of $100 \%$.

\section{Ethical statement}

The protocol of the study was approved by the research ethics committee of the Islamic Health Society (reference number: 1687.24251). Researchers and field workers conducted the study according to the research ethics guidelines laid down in the Declaration of Helsinki of the World Medical Association Assembly [23]. Participation in the study was voluntary and an informed consent was obtained from each participant. All the necessary measures to safeguard the participants' anonymity and the confidentiality of information were respected.

\section{Statistical analysis}

Data analyses were performed using the statistical software SPSS version 26.0 (IBM Corp. Released 2019.IBM
SPSS Statistics for windows, Version 26.0. Armonk, N.Y: IBM Corp). Descriptive statistics were reported using means along with standard deviations (SD) for continuous variables and frequency with percentages for categorical variables. The seroprevalence of IgG antibodies against SARS-COV-2 with 95\% CI was estimated as the proportion of individuals who had a positive result in the IgG band of the point-of-care test. We also calculated seroprevalences by age group, sex, area of residence and SARS-CoV-2 infection-related characteristics of study participants. In addition, seroprevalences were weighted by sex, age and area of residence to compensate for differences between the sample and the target profile by using the data provided by the Central Administration of Statistics (CAS) [13].

The weighted seroprevalences were further adjusted for the sensitivity and specificity of the assay using the formula [24]:

$$
\mathrm{P} \text { corrected }=(\mathrm{P}+\mathrm{Sp}-1) /(\mathrm{Se}+\mathrm{Sp}-1),
$$

where $\mathrm{P}$ is the weighted prevalence, Se is the sensitivity of the assay, and $\mathrm{Sp}$ is the specificity of the assay. The stratum seroprevalence and 95\% confidence intervals (CIs) of SARS-CoV-2 seropositivity were calculated.

The estimated number of subjects with previous COVID-19 was calculated by multiplying the seropositivity rates for each area of residence by the estimated population size. Results were compared with official numbers and rates of reported cases issued by the Lebanese Ministry of Public Health as of January 15, 2021 [5]. Ratios between population-wide seroprevalence estimates and the cumulative incidence of confirmed SARS-CoV-2 infections were calculated in the overall population and across governorates. The infection fatality ratio (IFR) was also calculated on the basis of the cumulative number of confirmed SARS-CoV-2 infection deaths as of January 15, 2021 divided by the number of infections inferred from seroprevalence data. Statistical significance was set at $\mathrm{p}$-value $<0.05$.

\section{Results}

\section{Characteristics of the study population}

Table 2 shows the demographic characteristics of participants. Between December 7, 2020 and January 15, 2021, a total of 2058 participants were included in the study. The mean participants age was $37.8 \pm 16.7$ years. Of the total, 1207 (58.6\%) of participants were women; $270(13.1 \%)$ had at least one comorbidity condition, 60 (2.9\%) reported a history of positive PCR testing for SARS-CoV-2 with $71.6 \%$ of them have had COVID-19 symptoms. 
Table 2 Characteristics of the study participants

\begin{tabular}{|c|c|c|}
\hline Characteristics & $\mathbf{N}$ & $\%$ \\
\hline Overall & 2058 & \\
\hline Age mean (SD) & $37.8 \pm 16.7$ & \\
\hline \multicolumn{3}{|l|}{ Age groups, years } \\
\hline$\leq 19$ & 293 & 14.2 \\
\hline $20-29$ & 403 & 19.6 \\
\hline $30-39$ & 366 & 17.8 \\
\hline $40-49$ & 360 & 17.5 \\
\hline $50-59$ & 320 & 15.5 \\
\hline$\geq 60$ & 200 & 9.7 \\
\hline Missing data & 116 & 5.6 \\
\hline \multicolumn{3}{|l|}{ Sex } \\
\hline Male & 851 & 41.4 \\
\hline Female & 1207 & 58.6 \\
\hline \multicolumn{3}{|l|}{ Comorbidities } \\
\hline Yes & 270 & 13.1 \\
\hline No & 1432 & 69.6 \\
\hline Don't know & 356 & 17.3 \\
\hline \multicolumn{3}{|c|}{ History of positive PCR testing for SARS-CoV-2 } \\
\hline Yes & 60 & 2.9 \\
\hline No & 1642 & 79.8 \\
\hline Don't know & 356 & 17.3 \\
\hline \multicolumn{3}{|c|}{$\begin{array}{l}\text { Presence of symptoms for who those who had a } \\
\text { history of positive PCR }\end{array}$} \\
\hline Yes & 43 & 71.6 \\
\hline No & 17 & 28.4 \\
\hline
\end{tabular}

$N$ number; \% percentage; $S D$ standard deviation

${ }^{a}$ Presence of at least symptoms for participants who had a history of positive PCR testing for SARS-CoV-2

\section{Prevalence of SARS-CoV-2 antibodies}

Table 3 presents the seroprevalence of SARS-CoV- 2 antibodies in the overall sample and stratified by sociodemographic characteristics. Of the 2058 participants, 329 were positive for IgG SARS-CoV-2 resulting in a crude seroprevalence of $16.0 \%$ (95\% CI of 14.4-17.6). Crude seroprevalence did not vary by sex $(15.6 \%$ versus $16.6 \%$ for males and females respectively, $\mathrm{p}$-value $=29.0)$ but did vary by age group from $11.7 \%$ (95\% CI of $8.6-14.8$ ) among adults aged $20-29$ years old to $19.2 \%$ (95\% CI of 15.1-23.3) among their counterparts aged 40-49 years $(p$-value $=08.0)$. Crude seroprevalence varied geographically from 29.5 (95\% CI of 21.1-37.9) in Baalbek El-Hermel to 6.1\% (95\% CI of 2.4-9.8) in Nabatieh (p-value $<0.0001$ ).

Weighted seroprevalences by demographic characteristics were calculated to match the 2019 Lebanese population census data. Overall, the weighed seroprevalence was $15.9 \%$ (95\% CI of 14.4 and 17.4 ) with $16.4 \%$ (95\% CI of 14.0 and 18.7) among females and $15.6 \%$ (95\% CI of 13.6 and 17.5) among males. The highest seroprevalence was observed in individuals aged between 40-49 years (19.2\%, 95\% CI of 15.1 and 23.3) and the lowest among those aged $20-29$ (12.2\%, 95\% CI of 9.2 and 15.2). Estimates varied markedly across provinces with the highest positive seroprevalence in Baalbek El-Hermel (29.8\%, 95\% CI of 21.0-38.6), followed by North Lebanon (18.2\%, 95\% CI of 12.2 and 24.2), Bekaa (18.0\%, 95\% CI of 11.5 and 24.5), Mount Lebanon (18.1\%, 95\% CI of 15.8 and 20.4), South Lebanon (12.6, 95\% CI of 9.5-15.7), Akkar (11.2\%, 95\% CI of 5.2 and 17.2), Beirut $(10.1 \%, 95 \% \mathrm{CI}$ of $5.3-14.9)$ and Nabatieh $(6.1 \%, 95 \%$ CI of $2.2-10)$. The prevalence of IgG antibody among individuals who had at least one comorbidity $(14.4 \%, 95 \% \mathrm{CI}$ of 10.2 and 18.6$)$ was lower compared to individuals with no comorbidities (16.3\%, 95\% CI of 14.4-18.2). Finally, the seroprevalence estimate in individuals who reported a history of positive PCR testing for SARS-CoV-2 was considerably higher $(63.3 \%, 95 \% \mathrm{CI}$ of $51.1-75.5)$ compared to individuals without history of positive PCR 14.3\% (95\% CI of 12.6-16.0). After adjusting for test performance, the population weight-adjusted seroprevalence was 18.5\% (95\% CI of 16.8-20.2). Across provinces, the highest positive seroprevalence was in Baalbek El-Hermel (34.1\%, 95\% CI of $25.3-42.9)$, followed by North Lebanon (21.3\%, 95\% CI of 15.0 and 27.6), Bekaa (21.0\%, 95\% CI of 14.3 and 27.7), Mount Lebanon (20.9\%, 95\% CI of 18.3 and 23.5), South Lebanon (14.6, 95\% CI of 10.4-18.8), Akkar (12.6\%, 95\% CI of 6.6 and 18.6), Beirut (11.4\%, 95\%CI of 6.5-16.3) and Nabatieh (7.0\%, 95\% CI of 3.3-10.9) (Fig. 2). IFR inferred from our seroprevalence data was estimated at $0.21 \%$.

\section{Comparison of seroprevalence results with reported cases by the Lebanese Ministry of Public Health}

As of January 15, 2021, the officially registered cumulative confirmed COVID-19 disease cases were 249,158 [5]. Our estimated overall seroprevalence of 18.5\% implies that 895,770 were previously infected by COVID-19. As a result, the overall estimated number of subjects with previous COVID-19 was three times higher than the cumulative number of confirmed cases. In the governorates, the seroprevalence estimate was higher than the cumulative reported case by a factor ranging between 1.6 to 13.9 times with the highest one reported in Akkar governorate. Regarding the percentage of underestimated cases, overall $13.4 \%$ of cases in the general population were underestimated. The highest percentages of underestimated cases were found in Baalbek El-Hermel (28.2\%) followed by North Lebanon (16.5\%), Bekaa (15.8\%), Mount Lebanon (15.7\%), Akkar (11.7\%), South Lebanon (11.5\%), and the lowest percentages were reported in Nabatieh (4.6\%) and Beirut (4.5\%) (Table 4). 
Table 3 Proportion positive with SARS-CoV-2 lgG

\begin{tabular}{|c|c|c|c|c|c|c|c|}
\hline Characteristics & $\mathrm{N}$ & $\begin{array}{l}\mathrm{N} \\
\text { Positive }\end{array}$ & Crude & $\mathrm{p}$-value & Weighted* & $\begin{array}{l}\text { Adjusted for test } \\
\text { performance }\end{array}$ & $\mathrm{p}$-value \\
\hline Overall & 2058 & 329 & $16.0(14.4 ; 17.6)$ & & $15.9(14.4 ; 17.4)$ & $18.5(16.8 ; 20.2)$ & \\
\hline Sex & & & & 0.29 & & & 0.60 \\
\hline Male & 1207 & 188 & 15.6(13.6;17.6) & & $15.6(13.6 ; 17.5)$ & $18.0(15.8 ; 20.2)$ & \\
\hline Female & 851 & 141 & $16.6(14.1 ; 19.1)$ & & $16.4(14.0 ; 18.7)$ & $19.2(16.6 ; 21.8)$ & \\
\hline Age groups (years) & & & & 0.08 & & & 0.08 \\
\hline$\leq 19$ & 293 & 45 & $15.4(11.3 ; 19.5)$ & & $15.0(11.2 ; 18.8)$ & $17.8(13.2 ; 22.2)$ & \\
\hline $20-29$ & 403 & 47 & $11.7(8.6 ; 14.8)$ & & $12.2(9.2 ; 15.2)$ & $13.5(10.2 ; 16.8)$ & \\
\hline $30-39$ & 366 & 63 & $17.2(13.3 ; 21.1)$ & & $17.1(13.5 ; 20.7)$ & $19.9(15.8 ; 24.0)$ & \\
\hline $40-49$ & 360 & 69 & $19.2(15.1 ; 23.3)$ & & $19.0(15.2 ; 22.8)$ & $22.2(17.9 ; 26.5)$ & \\
\hline $50-59$ & 320 & 52 & $16.3(12.3 ; 20.3)$ & & $15.7(11.9 ; 19.5)$ & $18.8(14.5 ; 23.1)$ & \\
\hline$\geq 60$ & 200 & 37 & $18.5(13.1 ; 23.9)$ & & $18.6(13.5 ; 23.7)$ & $21.4(15.7 ; 27.1)$ & \\
\hline Governorates & & & & $<0.0001$ & & & $<0.0001$ \\
\hline Baalbek El-Hermel & 112 & 33 & $29.5(21.1 ; 37.9)$ & & $29.8(21.0 ; 38.6)$ & $34.1(25.3 ; 42.9)$ & \\
\hline North Lebanon & 163 & 30 & $18.4(12.5 ; 24.3)$ & & $18.2(12.2 ; 24.2)$ & $21.3(15.0 ; 27.6)$ & \\
\hline Bekaa & 143 & 26 & $18.2(11.9 ; 24.5)$ & & $18.0(11.5 ; 24.5)$ & $21.0(14.3 ; 27.7)$ & \\
\hline Mount Lebanon & 925 & 167 & $18.1(15.6 ; 20.6)$ & & $18.1(15.8 ; 20.4)$ & $20.9(18.3 ; 23.5)$ & \\
\hline South Lebanon & 269 & 34 & 12.6(8.6;16.6) & & $12.6(9.5 ; 15.7)$ & $14.6(10.4 ; 18.8)$ & \\
\hline Akkar & 119 & 13 & $10.9(5.3 ; 16.5)$ & & $11.2(5.2 ; 17.2)$ & $12.6(6.6 ; 18.6)$ & \\
\hline Beirut & 162 & 16 & $9.9(5.3 ; 14.5)$ & & $10.1(5.3 ; 14.9)$ & $11.4(6.5 ; 16.3)$ & \\
\hline Nabatieh & 165 & 10 & $6.1(2.4 ; 9.8)$ & & $6.1(2.2 ; 10.0)$ & $7.0(3.1 ; 10.9)$ & \\
\hline Comorbidities & & & & 0.25 & & & 0.39 \\
\hline Yes & 270 & 39 & $14.4(10.2 ; 18.6)$ & & $16.2(12.1 ; 20.3)$ & $16.6(12.2 ; 21.0)$ & \\
\hline No & 1432 & 233 & $16.3(14.4 ; 18.2)$ & & $14.1(12.4 ; 15.8)$ & $18.8(16.8 ; 20.8)$ & \\
\hline $\begin{array}{l}\text { History of positive PCR test- } \\
\text { ing for SARS-CoV-2 }\end{array}$ & & & & $<0.0001$ & & & $<0.0001$ \\
\hline Yes & 60 & 38 & $63.3(51.1 ; 75.5)$ & & $63.2(51.7 ; 74.7)$ & $73.3(62.1 ; 84.5)$ & \\
\hline No & 1642 & 234 & $14.3(12.6 ; 16.0)$ & & $14.1(12.5 ; 15.7)$ & $16.5(14.7 ; 18.3)$ & \\
\hline
\end{tabular}

$N$ number; \%: percentage; lgG immunoglobulin G; $\mathrm{Cl}$ confidence interval

*Weighted by age group, sex, and governorates

\section{Discussion}

To the best of our knowledge, this is the first nationwide seroprevalence survey describing the prevalence of SARS-CoV-2 antibodies in the Lebanese population and comparing the estimated number of cases with the officially registered number of laboratory confirmed cases reported by the MOPH until January 15, 2021. Our results showed that the prevalence of SARS-CoV-2 antibodies was around $18 \%$ with an estimated cumulative total number of 895,770 COVID-19 cases. The overall estimated number of subjects with previous COVID-19 was three times higher than the officially reported cumulative number of confirmed cases. No significant differences in SARS-CoV-2 seropositivity regarding sex and age subgroups were found. However, significant differences were revealed across governorates.

The results of the current study revealed an overall estimated weighted seroprevalence of $18.5 \%$ which implies that the Lebanese general population is still susceptible to SARS-CoV-2 infection and has not reached the desired level of herd immunity (60-70\%). This low level could explain the ongoing wave epidemic intensity at the time of the study. A nationwide serosurvey conducted in India during the same period (December 2020 and January 2021) reported a higher seroprevalence estimate of $24 \%$ [18]. In addition, a Systematic review, summarizing data from January 1, 2020 to December 31, 2020 and including 9.3 million participants from 74 countries, has also revealed wide discrepancies in SARS-CoV-2 antibodies seroprevalences across geographic regions [25]. These discrepancies could be explained by the variation in the community spread of the virus and the applied preventive measures in each country.

Although earlier studies reported that women were less vulnerable to SARS-CoV-2 infection and less likely to show signs of COVID-19 compared to men [26-30], our findings were consistent with more recent studies that revealed no substantial differences in seroprevalence 


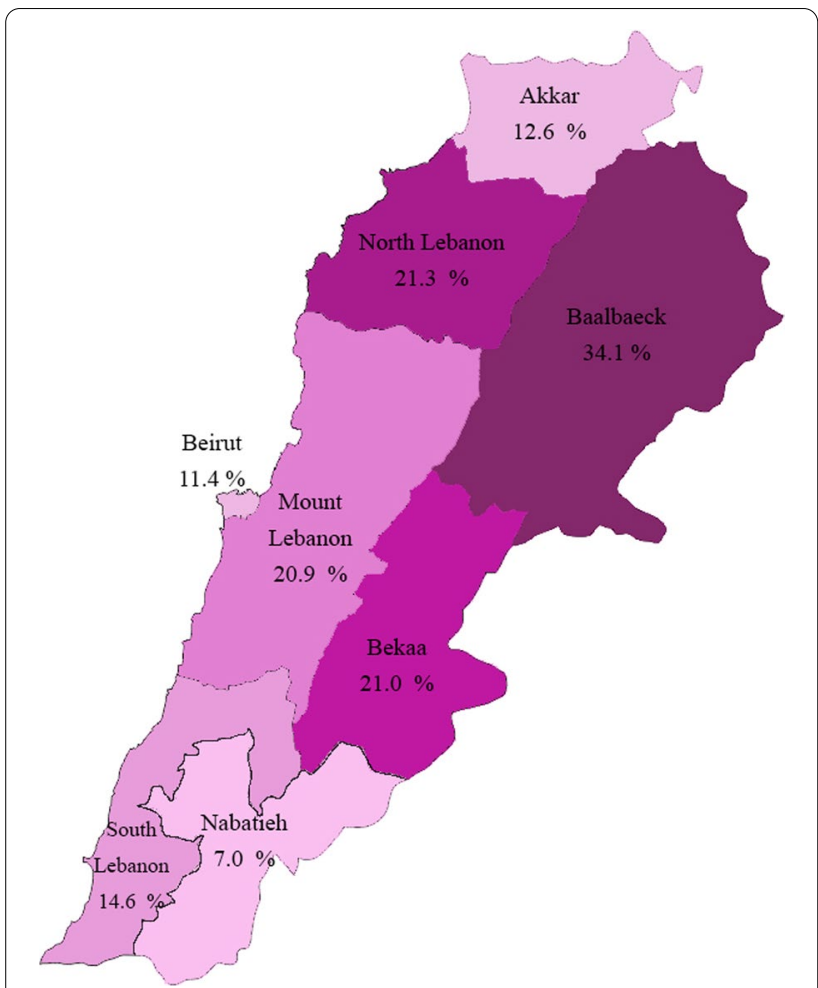

Fig. 2 Nationwide seroprevalence of SARS-CoV-2 in Lebanon

rates by sex [31, 32]. Regarding age group, our study didn't reveal any difference in seropositivity. This finding was inconsistent with a previous study which had found that people in the age group of 30-69 years had higher odds of seropositivity as compared to the younger population [32]. However, as expected, seropositivity varied significantly between governorates with the highest level found in Baalbek El-Hermel (weighed seroprevalence of $34.1 \%$ with $95 \% \mathrm{CI}$ of $25.3-42.9$ ) and the lowest one in Nabatieh (weighed seroprevalence of $7.0 \%$ with $95 \%$ CI of 3.1-10.9). These variations could be attributed to many factors, including variation in the community transmission across governorates, mitigation efforts, cultural practices, and the implementation of preventive measures.

Consistent with previous reports $[25,26]$, we found a significant difference between the officially registered number of COVID-19 cases and the extrapolated cumulative number of cases based on seroprevalence data. Approximately threefold more infections occurred in seroprevalence data what were ascertained by confirmed case counts, suggesting an underestimation of the epidemic extent in Lebanon. This ratio is relatively low compared to the ones reported in previous studies which ranged from 6.7-fold in South Asia to 602.5-fold in Sub-Saharan Africa [25]. Our findings also revealed that seroprevalence to cumulative case ratios varied substantially between governorates from 1.6-fold in Beirut to 13.9-fold in Akkar governorate. These variations could be explained by the limited availability and accessibility of testing in the socioeconomically deprived governorates such as Akkar and Baalbek-Hermel, as well as the increased number of undetected asymptomatic infections. Region-specific ratios are helpful in identifying areas that may be receiving potentially insufficient levels of testing.

As of January 15, 2021, the IFR calculated from officially registered COVID-19 cases and deaths was 0.75\% [5]. However, the inferred IFR from our seroprevalence

Table 4 Comparison of SARS-CoV-2 lgG results with reported cases by the Lebanese Ministry of Public Health

\begin{tabular}{|c|c|c|c|c|c|c|}
\hline Governorates & $\begin{array}{l}\text { Total } \\
\text { Population }\end{array}$ & $\begin{array}{l}\text { Weight-adjusted } \\
\text { Seroprevalence } \\
\%\end{array}$ & $\begin{array}{l}\text { Cumulative } \\
\text { number of } \\
\text { COVID-19* }\end{array}$ & $\begin{array}{l}\text { Estimated number of } \\
\text { subjects with previous } \\
\text { COVID-19** } \\
\text { n }\end{array}$ & $\begin{array}{l}\text { Ratio of estimated } \\
\text { number to Cumulative } \\
\text { number of COVID-19 }\end{array}$ & $\begin{array}{l}\text { Percentage of } \\
\text { underestimated } \\
\text { cases*** } \\
\%(95 \% \mathrm{Cl})\end{array}$ \\
\hline Beirut & 342,000 & 11.4 & 23,749 & 38,988 & 1.6 & $4.5(1.3 ; 7.7)$ \\
\hline Mount Lebanon & $2,032,000$ & 20.9 & 105,716 & 424,688 & 4.0 & $15.7(13.4 ; 18.0)$ \\
\hline Baalbek El-Hermel & 245,000 & 34.1 & 14,417 & 83,545 & 5.8 & $28.2(19.9 ; 36.5)$ \\
\hline Bekaa & 298,000 & 21.0 & 15,602 & 62,580 & 4.0 & $15.8(9.8 ; 21.8)$ \\
\hline North Lebanon & 638,000 & 21.3 & 30,805 & 135,894 & 4.4 & $16.5(10.8 ; 22.2)$ \\
\hline Akkar & 324,000 & 12.6 & 2,930 & 40,824 & 13.9 & $11.7(5.9 ; 17.5)$ \\
\hline South Lebanon & 584,000 & 14.6 & 18,242 & 85,264 & 4.7 & $11.5(7.7 ; 15.3)$ \\
\hline Nabatieh & 379,000 & 7.0 & 8910 & 26,530 & 3.0 & $4.6(1.4 ; 7.8)$ \\
\hline Lebanon & $4,842,000$ & 18.5 & 249,158 & 895,770 & 3.6 & $13.4(11.9 ; 14.9)$ \\
\hline
\end{tabular}

MOPH Lebanese Ministry of Public Health; IC confidence interval

*Cumulative number reported by MOPH until January 15, 2021

**Estimated number of subjects with previous COVID-19 calculated by multiplying the seropositivity rates for each governorate by the estimated population size

***Percentage of underestimated cases $=($ Estimated total number of seropositive - registered cases up to 15/1/2021)*100/total population 
(0.21\%) tended to be much lower. This comes in consistency with the study of Ioannidis [27]. Consequently, ongoing seroprevalence survey might be a better approach to complement surveillance data and to provide a more accurate picture of the pandemic actual burden.

It is worth mentioning that the serological surveys are the best tool to determine the spread of an infectious disease, particularly in the presence of asymptomatic cases or incomplete ascertainment of those with symptoms [32]. Different studies have reported a decrease of SARS-CoV-2 antibodies in the months following infection [15, 33, 34]. Most convalescent people who recover from SARS-CoV-2 do not have high levels of neutralizing activity [35]. This possible loss of immunity over time must be considered when interpreting seroprevalence studies for SARS-CoV-2.

Our study has several strengths: This is the first national study concerning seroprevalence of SARSCoV-2 in Lebanon. In this respect, our study provides new information about the true number of COVID-19 cases in our country. The sample was designed to be representative in terms of governorates. Additionally, the overall prevalence estimates were adjusted not only for sex and age groups, but also for test performance to make the findings representative of the study population. The non-response rate at the household level was relatively low compared to other population-based survey $[15,17$, 30-36]. Finally, Individuals with current SARS-CoV-2 symptoms were excluded to avoid an inflated proportion of individuals with negative tests which could underestimate the seroprevalence. Despite these strengths, our study has some limitations that should be noted. For instance, the collected data was based on self-reported information which makes it prone to the social desirability and recall biases. In addition, some of the participants were unaware or refused to answer some of the survey questions which may result in non-response bias. However, it is expected that the weighting controlled the non-response bias of the present survey. Considering the specificities of used tests and the cross-reactivity with other viruses such as endemic non-SARS-CoV-2, we cannot completely rule out the possibility of false results that might overestimate the seroprevalence among the study population. Finally, the cumulative number of officially laboratory-confirmed COVID-19 cases in Lebanon have increased substantially since the completion of the serosurvey, meaning that, the results reported in this study does not represent the true seroprevalence at the time of writing and publication of this study. Further studies are needed to investigate other sociodemographic characteristics affecting SARS-COV-2 seroprevalence such occupation (Health worker/Frontline workers) and economic classes.

\section{Conclusions}

Our results suggest that at the time of writing the study, the Lebanese population was still susceptible to SARS-CoV-2 infection and far from achieving herd immunity. Infection rates based on surveillance data considerably underestimated the actual burden of the SARS-CoV-2 infection in Lebanon. Our findings represent an important contribution to the surveillance of the SARS-CoV-2 infection in Lebanon and to the understanding of how this virus spreads. As the number of SARS-CoV-2 infection cases is still growing rapidly, seroprevalence surveillance should be sustained and is necessary to gain insight into the transmission dynamics of SARS-CoV-2 infection. Furthermore, continued surveillance for COVID-19 cases and maintaining effective preventive measures are recommended to control the epidemic spread in conjunction with a national vaccination campaign to achieve the desired level of herd immunity against COVID-19. Last but not the least, additional investigations are required, especially longitudinal serological studies using the gold standard test, to monitor the extent of the pandemic and determine the persistence of antibody-mediated immunity.

\section{Abbreviations}

CAS: Central Administration of Statistics; Cl: Confidence interval; COVID-19: Coronavirus Disease 2019; IFR: Infection fatality ratio; IgG: Immunoglobulin G; MOPH: Ministry of Public Health; RT-PCR: Reverse Transcription Polymerase Chain Reaction; SARS-CoV-2: Severe acute respiratory syndrome coronavirus 2; SD: Standard deviation; WHO: Word Health Organization.

\section{Supplementary Information}

The online version contains supplementary material available at https://doi. org/10.1186/s12879-022-07031-z.

Additional file 1: Table SA. The number of participants according to Lebanese governates and villages.

Acknowledgements

The authors are grateful to all the health care workers from the Islamic Health Society who collaborated in this study and to all participants who voluntarily took part in the study.

\section{Authors' contributions}

Conceptualization, $\mathrm{AH} ; \mathrm{RH}$ and $\mathrm{SM}$; methodology, $\mathrm{AH}$; $\mathrm{RH}$; and $\mathrm{SM}$; software, $\mathrm{SM}$ and $\mathrm{RH}$; validation, $\mathrm{AH}, \mathrm{LAA}$ and $\mathrm{RH}$; formal analysis, $\mathrm{AH}, \mathrm{FA}, \mathrm{RH}$, and $\mathrm{LAA}$; investigation, $\mathrm{RH}$; $\mathrm{AH}$; and $\mathrm{SM}$; resources, $\mathrm{AH}$; $\mathrm{RH}$; data curation, $\mathrm{RH}$ and $\mathrm{AH}$; writing-original draft preparation, $\mathrm{RH} ; \mathrm{GS} ; \mathrm{LAA}$ and $\mathrm{AH}$ writing - review and editing, $\mathrm{RH}$; GS; LAA and $\mathrm{AH}$ visualization, $\mathrm{AH} ; \mathrm{FA}$ and LAA; supervision, $\mathrm{AH}$; project administration, $\mathrm{AH} ; \mathrm{RH}$ and $\mathrm{SM}$. All authors read and approved the final manuscript.

Funding

This research received no external funding.

Availability of data and materials

The datasets used and/or analyzed during the current study are available from the corresponding author on reasonable request. 


\section{Declarations}

\section{Ethics approval and consent to participate}

The study was conducted according to the guidelines of the Declaration of Helsinki, and approved by the Ethics Committee of the Islamic health society on October 9, 2020 (Reference Number: 1687.24251). Informed written consent was obtained from all subjects involved in the study.

\section{Consent for publication}

Not applicable.

\section{Competing interests}

The authors declare no competing interests.

\section{Author details}

${ }^{1}$ General Director of Islamic Health Society, Baabda, Lebanon. ${ }^{2}$ Department of Research, Islamic Health Society, Baabda, Lebanon. ${ }^{3}$ Faculty of Public Health, Lebanese University, Fanar, Lebanon. ${ }^{4}$ Laboratory of Molecular Biology and Cancer Immunology (COVID 19 Unit), Faculty of Science, Lebanese University, Hadath, Lebanon. ${ }^{5}$ Department of Informatics, Islamic Health Society, Baabda, Lebanon. ${ }^{6}$ Ministry of Public Health, Beirut, Lebanon. ${ }^{7}$ Medical Care Laboratory Medicine, Faculty of Public Health, Lebanese University, Zahle, Lebanon. ${ }^{8}$ Neuroscience Research Center, Faculty of Medical Sciences, Lebanese University, Beirut, Lebanon. ${ }^{9}$ Epidemiological Surveillance Program, Ministry of Public Health, Beirut, Lebanon.

Received: 26 April 2021 Accepted: 5 January 2022

Published online: 10 January 2022

\section{References}

1. Coronavirus Disease (COVID-19) —Events as They Happen. Available online: https://www.who.int/emergencies/diseases/novel-coronavirus2019/events-as-they-happen. Accessed 5 Mar 2021.

2. Gao Z, Xu Y, Sun C, Wang X, Guo Y, Qiu S, Ma K. a systematic review of asymptomatic infections with COVID-19. J Microbiol Immunol Infect. 2021;54:12-6. https://doi.org/10.1016/j.jmii.2020.05.001.

3. Transmission of SARS-CoV-2: Implications for Infection Prevention Precautions. Available online: https://www.who.int/news-room/commentaries/ detail/transmission-of-sars-cov-2-implications-for-infection-preventionprecautions. Accessed 5 Mar 2021.

4. El Deeb O, Jalloul M. The dynamics of COVID-19 spread: evidence from Lebanon. Math Biosci Eng. 2020;17:5618-32.

5. Ministry of Public Health (MOPH). Monitoring of COVID-19 infection in Lebanon-15/1/2021. https://www.moph.gov.lb/en/Media/view/ 43750/1/monitoring-of-covid-19-. Accessed 16 Jan 2021.

6. MRC Centre for Global Infectious Disease Analysis, Imperial College London. Situation report for COVID-19: Lebanon, 2021-08-06. Available https://mrc-ide.github.io/global-Imic-reports/LBN/. Accessed 21 Aug 2021

7. Ministry of Public Health (MOPH). Monitoring of COVID-19 infection in Lebanon-7/8/2021. https://www.moph.gov.lb/en/Media/view/ 43750/1/monitoring-of-covid-19-. Accessed 25 July 2021.

8. La Marca A, Capuzzo M, Paglia T, Roli L, Trenti T, Nelson SM. Testing for SARS-CoV-2 (COVID-19): a systematic review and clinical guide to molecular and serological in-vitro diagnostic assays. Reprod Biomed Online. 2020;41:483-99. https://doi.org/10.1016/j.rbmo.2020.06.001.

9. Bizri AR, Khachfe HH, Fares MY, Musharrafieh U. COVID-19 pandemic: an insult over injury for Lebanon. J Community Health. 2020. https://doi.org/ 10.1007/s10900-020-00884-y.

10. Unity Studies: Early Investigation Protocols. Available online: https://www. who.int/emergencies/diseases/novel-coronavirus-2019/technical-guida nce/early-investigations. Accessed 5 Mar 2021.

11. Pollán M, Pérez-Gómez B, Pastor-Barriuso R, Oteo J, Hernán MA, PérezOlmeda M, Sanmartín JL, Fernández-García A, Cruz I, de Larrea NF, et al. Prevalence of SARS-CoV-2 in Spain (ENE-COVID): a nationwide, population-based seroepidemiological study. Lancet. 2020;396:535-44. https://doi.org/10.1016/S0140-6736(20)31483-5.
12. Stringhini S, Wisniak A, Piumatti G, Azman AS, Lauer SA, Baysson H, Ridder DD, Petrovic D, Schrempft S, Marcus K, et al. Seroprevalence of anti-SARS-CoV-2 lgG antibodies in Geneva, Switzerland (SEROCoV-POP): a population-based study. Lancet. 2020;396:313-9. https://doi.org/10.1016/ S0140-6736(20)31304-0.

13. Hallal PC, Hartwig FP, Horta BL, Silveira MF, Struchiner CJ, Vidaletti LP, Neumann NA, Pellanda LC, Dellagostin OA, Burattini MN, et al. SARS-CoV-2 antibody prevalence in Brazil: results from two successive nationwide serological household surveys. Lancet Glob Health. 2020;8:e1390-8. https://doi.org/10.1016/S2214-109X(20)30387-9.

14. Poustchi H, Darvishian M, Mohammadi Z, Shayanrad A, Delavari A, Bahadorimonfared A, Eslami S, Javanmard SH, Shakiba E, Somi MH, et al. SARS-CoV-2 antibody seroprevalence in the general population and high-risk occupational groups across 18 cities in Iran: a population-based cross-sectional study. Lancet Infect Dis. 2020. https://doi.org/10.1016/ S1473-3099(20)30858-6.

15. Havers FP, Reed C, Lim T, Montgomery JM, Klena JD, Hall AJ, Fry AM, Cannon DL, Chiang C-F, Gibbons A, et al. Seroprevalence of antibodies to SARS-CoV-2 in 10 sites in the United States, March 23-May 12, 2020. JAMA Intern Med. 2020. https://doi.org/10.1001/jamainternmed.2020. 4130.

16. Borges LP, Martins AF, de Melo MS, de Oliveira MGB, de RezendeNeto JM, Dósea MB, Cabral BCM, Menezes RF, Santos AA, Matos ILS, et al. Seroprevalence of SARS-CoV-2 lgM and lgG antibodies in an asymptomatic population in Sergipe, Brazil. Rev Panam Salud Publica. 2020. https://doi. org/10.26633/RPSP.2020.108.

17. Khalagi K, et al. Prevalence of COVID-19 in Iran: results of the first survey of the Iranian COVID-19 serological surveillance programme. Clin Microbiol Infect. 2021. https://doi.org/10.1016/j.cmi.2021.06.002.

18. Murhekar MV, et al. SARS-CoV-2 seroprevalence among the general population and healthcare workers in India, December 2020-January 2021. Int J Infect Dis. 2021;108:145-55.

19. Grant MC, et al. The prevalence of symptoms in 24,410 adults infected by the novel coronavirus (SARS-CoV-2; COVID-19): a systematic review and meta-analysis of 148 studies from 9 countries. PLOS ONE. 2020;15(6):e0234765

20. Epitools-Sample Size to Estimate a Proportion or Appar. Available online: https://epitools.ausvet.com.au/oneproportion. Accessed 5 Mar 2021

21. Noureddine FY, et al. The emergence of SARS-CoV-2 variant(s) and its impact on the prevalence of COVID-19 cases in the Nabatieh Region, Lebanon. Med Sci. 2021:9(2):40.

22. Central Administration of Statistics - about Lebanon. Available online: http://www.cas.gov.lb/index.php/about-lebanon-en. Accessed 5 Mar 2021.

23. Williams JR. The declaration of Helsinki and public health. Bull World Health Organ. 2008:86:650-2. https://doi.org/10.2471/BLT.08.050955.

24. Rogawski McQuade ET, Guertin KA, Becker L, Operario D, Gratz J, Guan D, Khan F, White J, McMurry TL, Shah B, et al. Assessment of seroprevalence of SARS-CoV-2 and risk factors associated with COVID-19 infection among outpatients in Virginia. JAMA Netw Open. 2021:4:e2035234. https://doi.org/10.1001/jamanetworkopen.2020.35234.

25. Bobrovitz N, et al. Global seroprevalence of SARS-CoV-2 antibodies: a systematic review and meta-analysis. PLoS ONE. 2021;16(6):e0252617.

26. Byambasuren $\mathrm{O}$, et al. Comparison of seroprevalence of SARS-CoV-2 infections with cumulative and imputed COVID-19 cases: systematic review. PLoS ONE. 2021;16(4):e0248946.

27. Ioannidis JPA. Infection fatality rate of COVID-19 inferred from seroprevalence data. Bull World Health Organ. 2021;99(1):19-33f.

28. Chen $\mathrm{N}$, et al. Epidemiological and clinical characteristics of 99 cases of 2019 novel coronavirus pneumonia in Wuhan, China: a descriptive study. Lancet. 2020;395(10223):507-13.

29. Wang D, et al. Clinical course and outcome of 107 patients infected with the novel coronavirus, SARS-CoV-2, discharged from two hospitals in Wuhan, China. Crit Care. 2020;24(1):188.

30. Murhekar MV, et al. Prevalence of SARS-CoV-2 infection in India: findings from the national serosurvey, May-June 2020. Indian J Med Res. 2020;152(1 \& 2):48-60.

31. The Sex, Gender and COVID-19 Project | Global Health 50/50 [Internet]. [cited 2021 Jan 17]. Available from: https://globalhealth5050.org/the-sexgender-and-covid-19-project/. 
32. Metcalf CJE, Farrar J, Cutts FT, Basta NE, Graham AL, Lessler J, Ferguson NM, Burke DS, Grenfell BT. Use of serological surveys to generate key insights into the changing global landscape of infectious disease. Lancet. 2016;388:728-30. https://doi.org/10.1016/S0140-6736(16)30164-7.

33. Stefanelli P, Bella A, Fedele G, Pancheri S, Leone P, Vacca P, Neri A, Carannante A, Fazio C, Benedetti E, et al. Prevalence of SARS-CoV-2 IgG antibodies in an area of northeastern Italy with a high incidence of COVID-19 cases: a population-based study. Clin Microbiol Infect. 2020. https://doi. org/10.1016/j.cmi.2020.11.013.

34. Naaber P, Hunt K, Pesukova J, Haljasmägi L, Rumm P, Peterson P, Hololejenko J, Eero I, Jõgi P, Toompere K, et al. Evaluation of SARS-CoV-2 lgG antibody response in PCR positive patients: comparison of nine tests in relation to clinical data. PLoS ONE. 2020;15: e0237548. https://doi.org/10. 1371/journal.pone.0237548.

35. Lee WT, Girardin RC, Dupuis AP II, Kulas KE, Payne AF, Wong SJ, Arinsburg S, Nguyen FT, Mendu DR, Firpo-Betancourt A, et al. Neutralizing antibody responses in COVID-19 convalescent sera. J Infect Dis. 2021;223:47-55. https://doi.org/10.1093/infdis/jiaa673.

36. Lopez L, et al. Seroprevalence of anti-SARS-CoV-2 lgG antibodies in the staff of a public school system in the midwestern United States. PLoS ONE. 2021;16(6):e0243676.

\section{Publisher's Note}

Springer Nature remains neutral with regard to jurisdictional claims in published maps and institutional affiliations.

- fast, convenient online submission

- thorough peer review by experienced researchers in your field

- rapid publication on acceptance

- support for research data, including large and complex data types

- gold Open Access which fosters wider collaboration and increased citations

- maximum visibility for your research: over $100 \mathrm{M}$ website views per year

At BMC, research is always in progress.

Learn more biomedcentral.com/submissions 